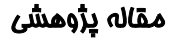 \\ بررسى فراوانى ناهنجاريهاى آشكاردر نوزادان متولد شده در بيمارستان امير المومنين سيستان
}

سوسن حسينى 'وr، عباس نيك روش"، زهره سادات هاشمى"، ناهيد رخشى ه"

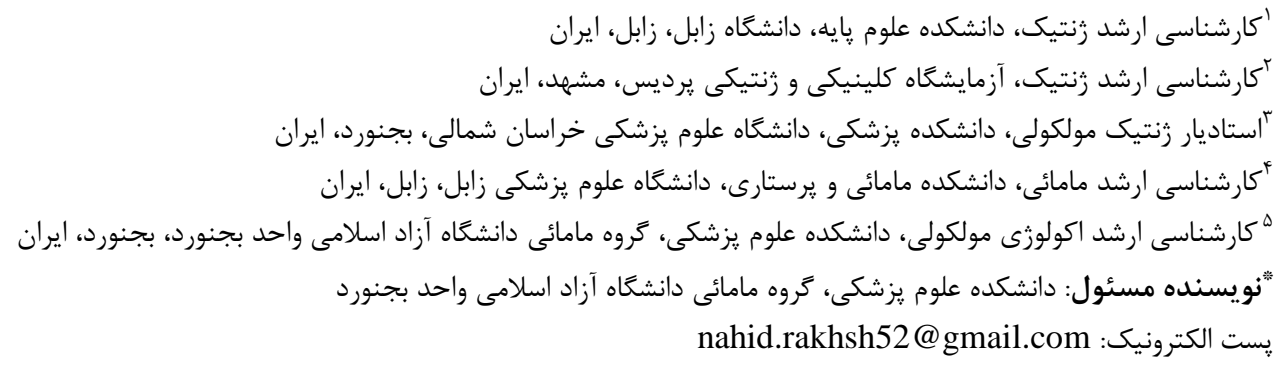

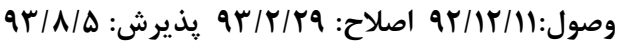

جكيده

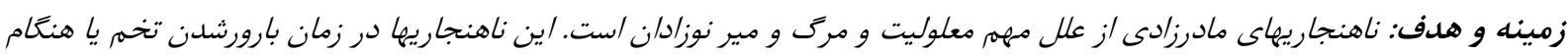

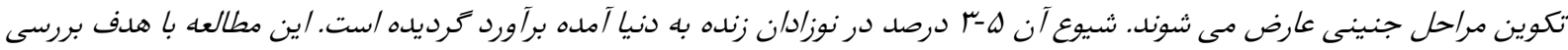

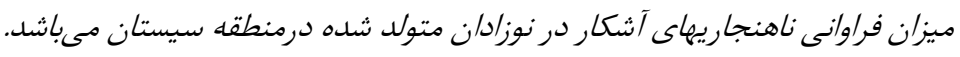

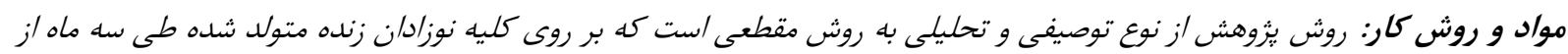

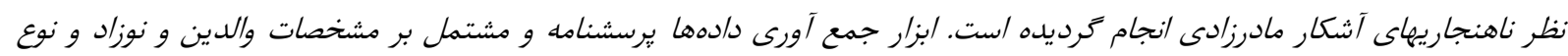

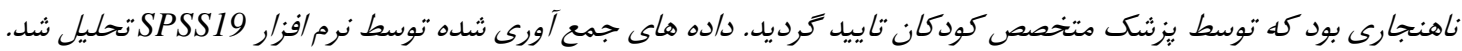

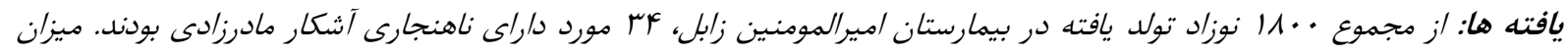

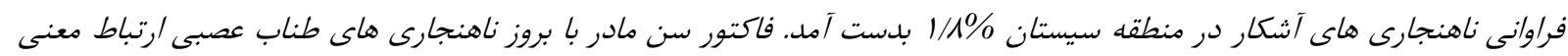

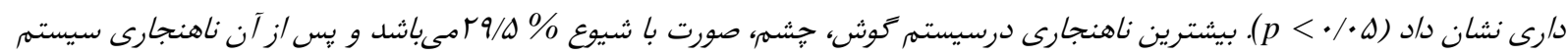
عصبى قرار دارد. نتيجه كيرى: يافته هاى /ين مطالعه نشان ميدهد كه ميزان بروز ناهنجارى مادرزادى در نوزادان زنده متولد شده در شهر زابل مشابه مطالعات بيشين در زمينه ناهنجارى مي بافي باشد.

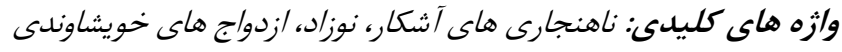

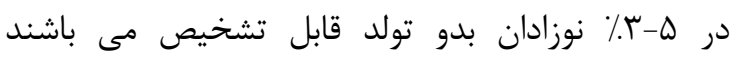
مقدمه

ناهنجاريهاى هنگام تولد از علل اصلى مرى نوزاد مي باشد بزركترين سرمايه هر كشور نسل آينده سالم، دانا، با هوش و ينجمين علت بالقوه مرگ درافراد و عامل مهمم معلوليتها و خلاق مى باشد در كشورهاى يیشرفته سرمايه كذاريهاى

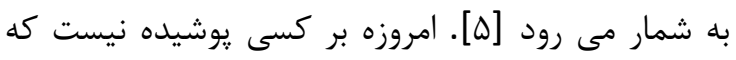

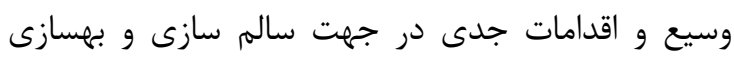

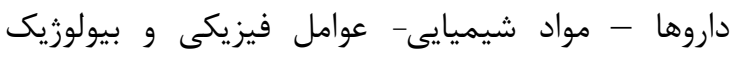
نسل آينده انجام مى شود [1]

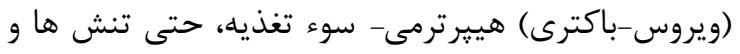

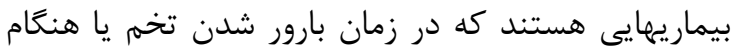

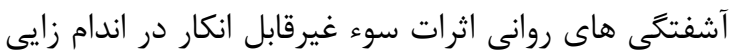

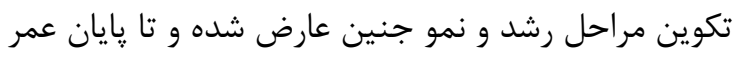
باعث معلوليت، بيمارى و يا مرك مى شوند اين ناهنجارئر اريها 
در ناهنجارى هاى مازور شايع است و حدود ب درصد تمام

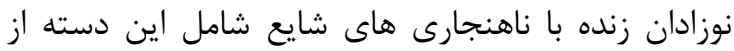

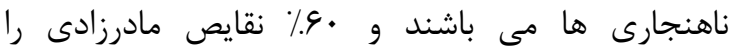

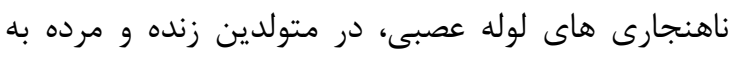

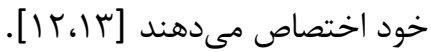
آنومالى مينور يا ناهنجارى هاى خفيف يك تغيير ساختارى را شامل مىشود كه نياز به درمان ندارند يا با نائ

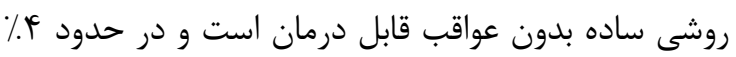
جمعيت مشاهده مى شوند، مانند زايده يوستى جلو كوش

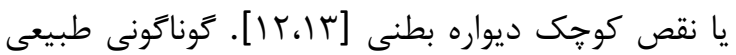

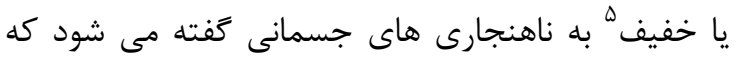

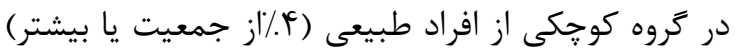

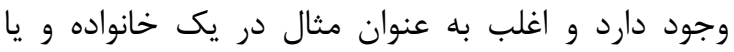

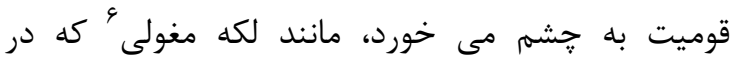
سياهيوستان و آسيايى ها مشاهده مى كَردد [10].

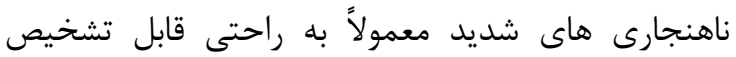
هستند، اما ناهنجارى هاى خفيف نياز به معاينات دقيقتر دارند، اهميت ناهنجارى هاى خفيف از آن رو است كه ثاه جزيى از يك سندرم خاص هستند و شناسايى آنها به تشخيص سندرم كمك مى كند و در برخى مواقع نشانكَر

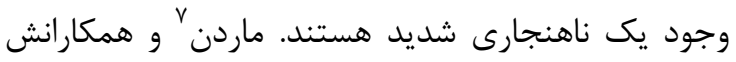
طى مطالعاتشان با مشاهده ناهنجارى هاى خفيف درد

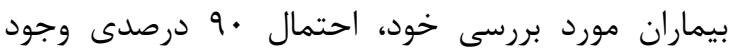

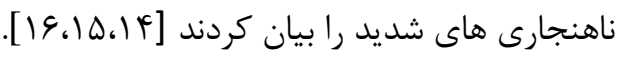

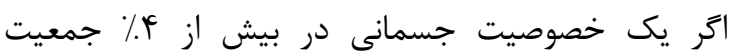
مشاهده شود، يك وارياسيون طبيعى محسوب مى تردد و در صورتى كه با توجه به سابقه خانوادگى و خصوصني

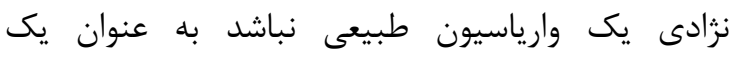

ناهنجارى خفيف تلقى مى شود [11] شيوع متفاوت ناهنجارى ها در نزاد هاى مختلف به اثبات

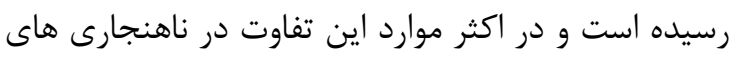
منفرد مشاهده مىشود [IV] ممكن است يك خصوصيت جسمانى با توجه به ميزان شيوع آن در يك نزاد ناهنجارى خفيف و در نزيت جناد ديكر

5 -Normal Variation or Minor Variant 6 -Mongolian Spot

7 -Marden
و شكل گيرى رويان دارند. لذا با شناختن عوامل

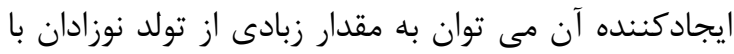

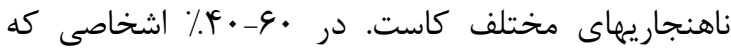
داراى ناهنجارى بدو تولد مى باشند، علت ناهنجارى نا

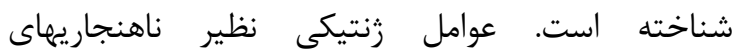
كروموزومى و زنهاى جهش يافته رقمى حدود ها 1\%، عوامل

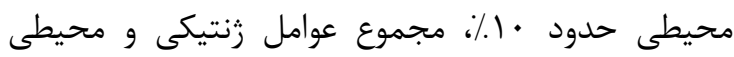

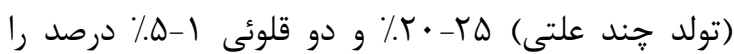

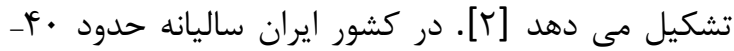

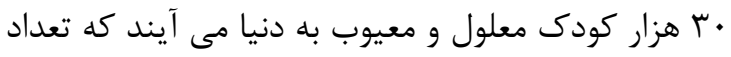

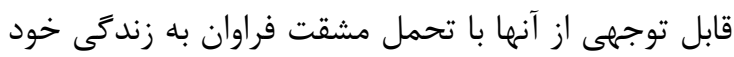
ادامه مى دهند. اين كودكان نه تنها خود داراى مشكلات إنات جسمى- روحى و روانى فراوانى هستند بلكه براى خانواده

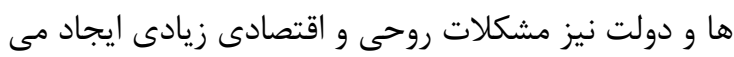

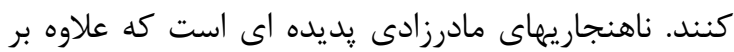
ناتوانى ها و مشكلاتى كه براى هر فرد ايجاد مى كند، بر

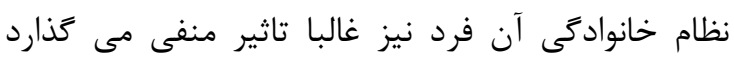

عليرغم پيشرفت هاى حاصل شده در اتيولوزى وياتوزنز

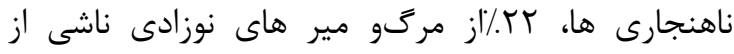
ناهنجارى هاى بزرى مادرزادى مى باشد. هزينه مراقبت

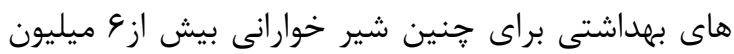

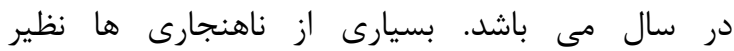

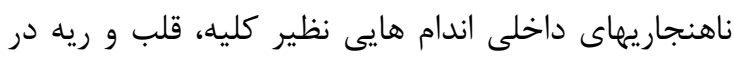
زمان تولد ممكن است قابل مشاهده نباشند و فقط با فائ افزايش سن آشكار مى گردند [^]. به همين دليل شيوع

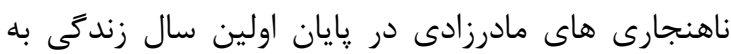

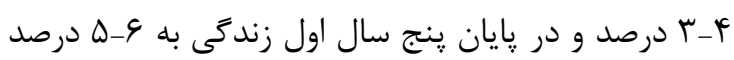
مىرسد [9]. ناهنجارى هاى مادرزادى از نظر شدت

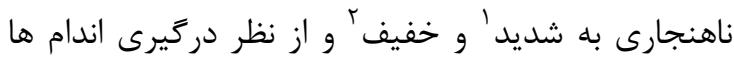

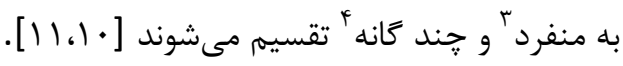
آنومالى مازور شامل آن دسته از ناهنجارى هايى مى شود كه نياز به جراحى ترميمى و مداخلات درمانى دارند مانند:

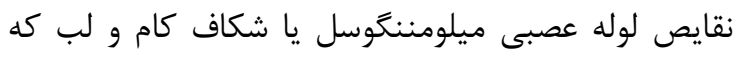

1 -Major

2 -Minor

3 -Isolated

4 -Multiple 
لكن، فوكوميليا)، گَوارشى (آنوس بسته، شكاف كام، شكاف لب، امفالوسل)، سيستم عصبى (مننگُوميلوسل، مننگُوسل، هيدروسفال، ميكروسفال، اسيينابيفيدا)، ادراى -تناسلى

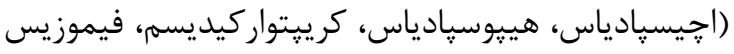
و ابهام جنسى)، ناهنجارى هاى كروموزومى (سندرم ها) و و

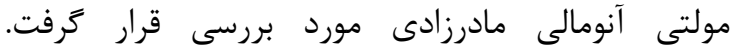
ابزاركردآورى داده ها، فرم يرسش نامه بود كه شامل

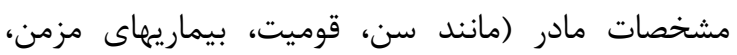
بيمارى در طول دوره باردارى، سابقه مصرف دارو شامل

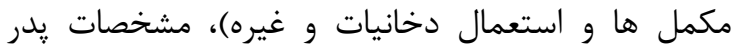

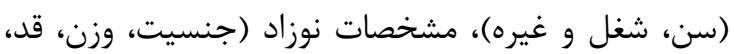

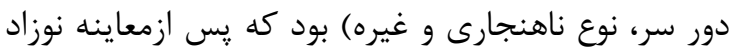
توسط متخصصين اطفال، بوسيله ماماى همكار يزوهشكر

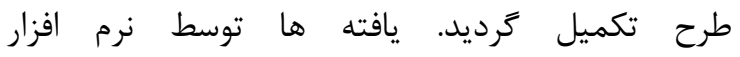
آمارى SPSS19 مورد تجزيه و تحليل قرار كرفت. آزمون هاى آمارى مورد استفاده مجذور كاى براى متغيرهاى كيفى و آزمون T-test براى متغيرهاى كمى بود. حداكثر

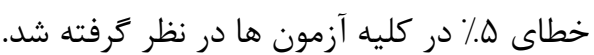

يافته ها

در اين مطالعه نتايج مربوط به معاينه . ㅅ| نوزاد كه در سال |

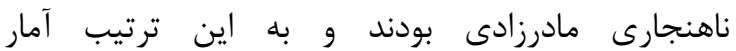

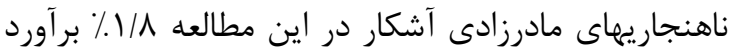

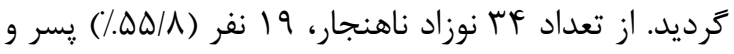
بقيه دختر بودند (جدول (). بيشترين ميزان ناهنجاريهاى

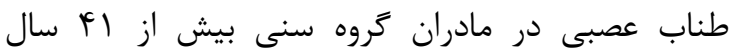
مشاهده شد كه دليل بر تاييد نقش سن مادر بر نوع ناهنجارى نوزادان مى باشد. تعداد ناهنجارى آنوماليهاى

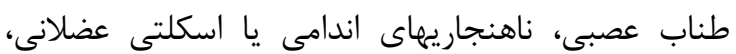
ناهنجاريهاى صورت، شكم و ناهنجاريهاى سيستم ادرارى

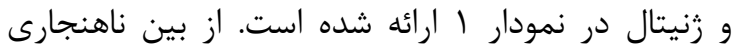

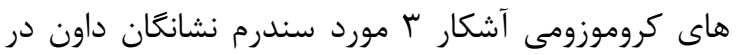
طى اين يزوهش مشاهده شد ساير ناهنجارى هاى

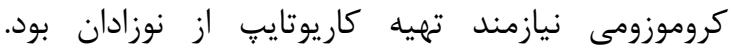
بيشترين ميزان بروز ناهنجارى مربوط به ناهنجاريهاى

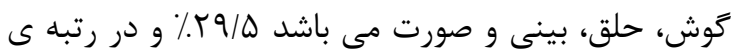

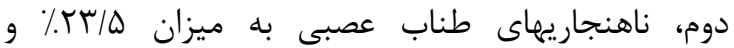

وارياسيون طبيعى تلقى گردد مانند لكه مغولى [1ه]. بررسىها نشان مىدهد كه حدود ها إ از علل مرى نوزادان، ناهنجاريهاى شديد مىباشد؛ شيوع ناهنجارى ها در نوزادان كم وزن \ برابر و در نوزادان نارس

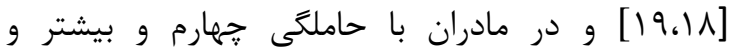

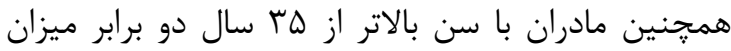
كلى ناهنجارىها در تولدهاى زنده كزارش شده است آنادي

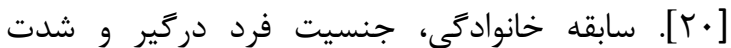
بيمارى در خانواده بر بروز مجدد آن ناهنجارى در فرزندان

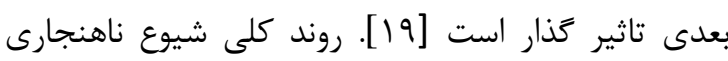
هاى مادرزادى در كشورهاى مختلف رو به كاهش است

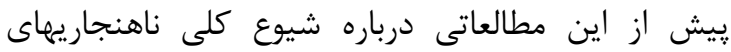

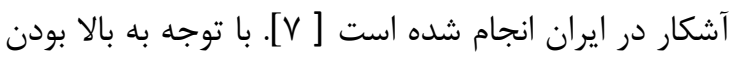

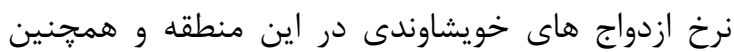

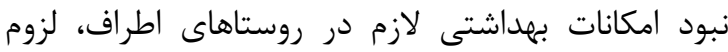
ضرورت انجام اين مطالعه را آشكار مىسازد. هدف از اين مطالعه بررسى ميزان فراوانى ناهنجاريهاى

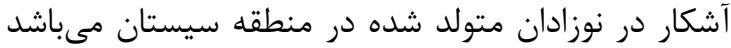

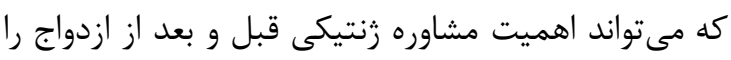
روشن كرده و در صورت امكان با تشخيص قبل از تولد، از از تولد كودكانى با ناهنجارى هاى شديد و آشكار جلوكيرى

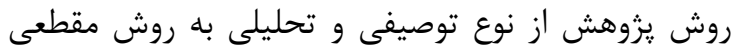
است كه بر روى كليه نوزادان زنده متولد شده طى سه ماه

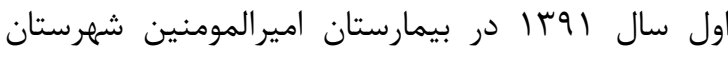
زابل انجام كرديد. از آنجايى كه بيمارستان اميرالمومنين

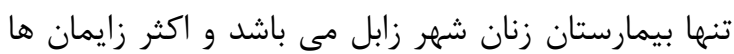
در اين مركز انجام مى شود، لذا مطالعه در اين بيمارستان

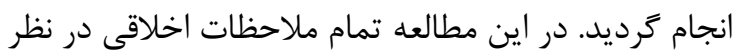

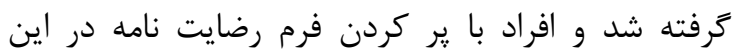
يزوهش وارد شدند. در مطالعه حاضر تمام نوزادان زنده متولد شده در تاريخ ذكر شده كه داراى ناهنجارى

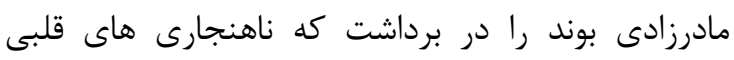
عروقى (غير طبيعى قلب، همانزيوم)، اسكلتى -عضلانى

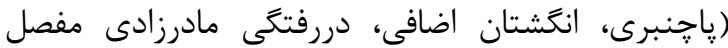




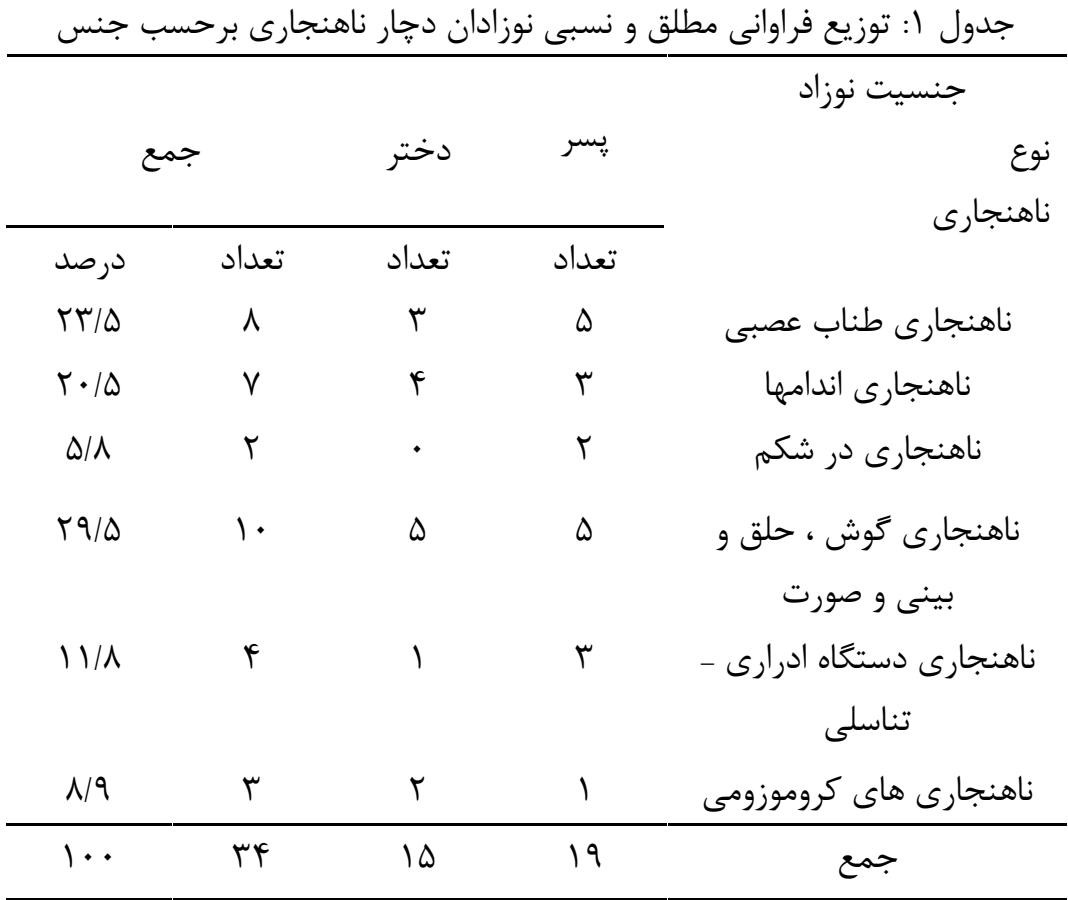

نمودار ا: تعداد نوزادان زنده متولد شده به تفكيك نوع ناهنجارى هاى مادرزادى آشكار در سه ماه اول سال | آ إ در بيمارستان اميرالمومنين شهرستان زابل.

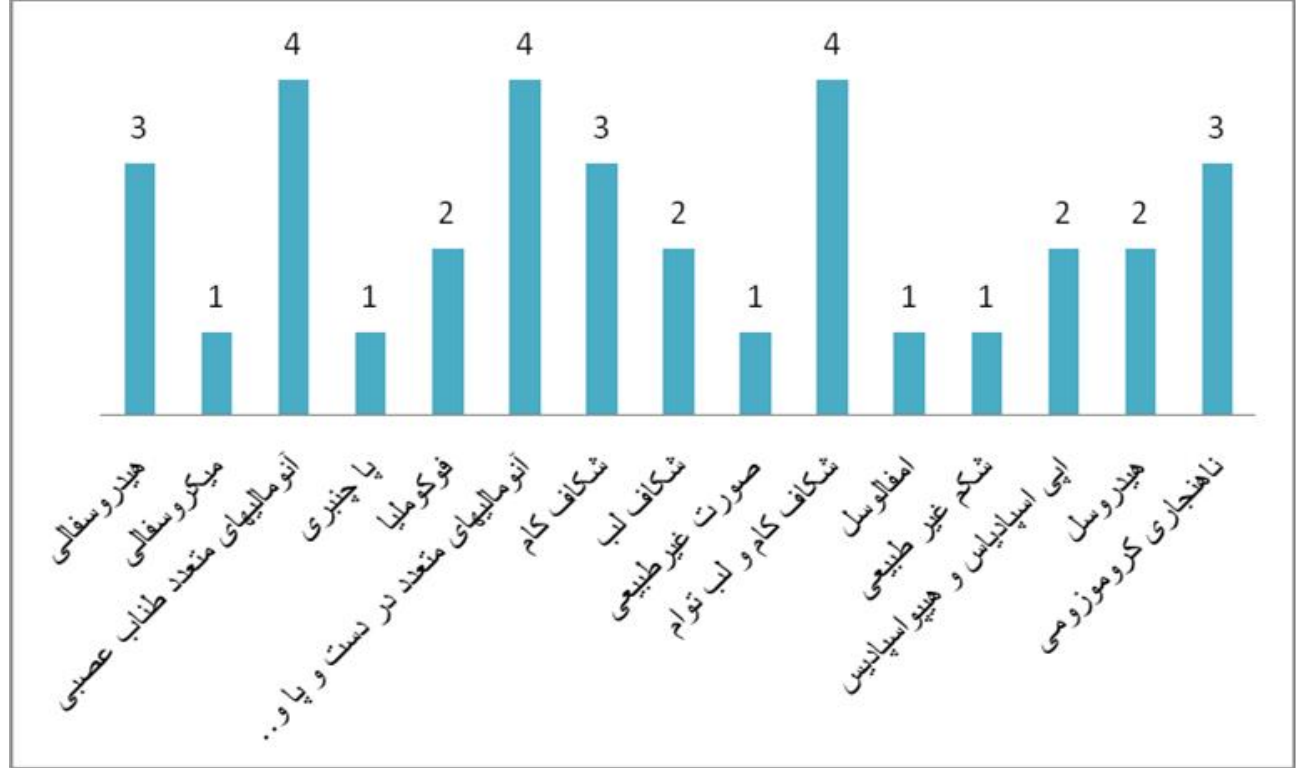


نوزاد متولد شده T/A درصد ناهنجارى هاى آشكار مادرزادى را كزارش كردند. ناهنجاريهاى مادرزادى در درائ مراحل مختلف رشد و تكامل جنينى انسان اتفاق مى افتلد،

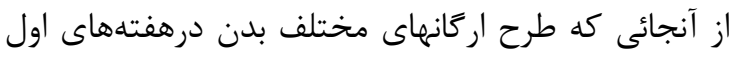

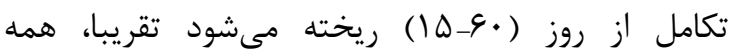

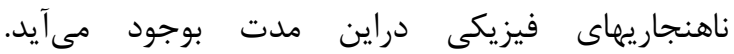

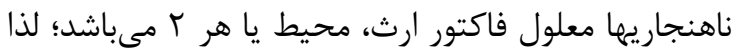

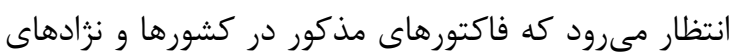
مختلف به طور متفاوت اثر كرده و تعداد ناهنجاريهاى

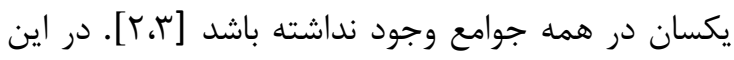

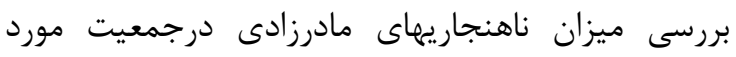
مطالعه //1 درصد بدست آمده است كه اين رقم با ارقامى دمادي كه از يزوهش مناطق ديكر ززارش شده است، هماهنكى

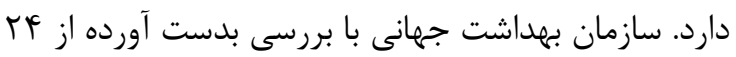

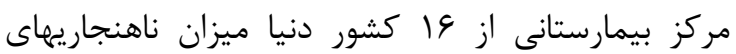
مادرزادى آشكار را I/TV درصد كزارش كرده است. در تحقيق شاه محمدى و همكاران ميزان شيوع ناهنجارى

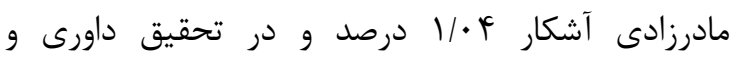

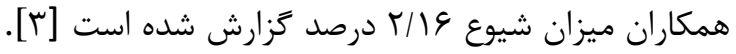
بايد دانست كه حد قاطع براى انحراف از وضعيت نرمال

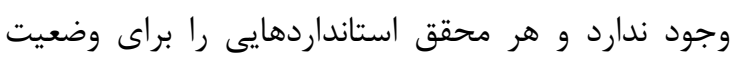
يك فرد نرمال بيشنهاد كرده و انحراف از آن استانداردها

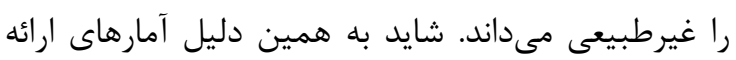

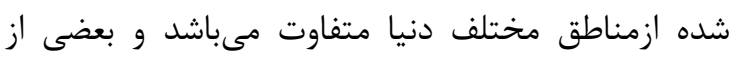
ناهنجاريهاى خفيف در محاسبات وارد نمىشود [F]. عواملى مانند بيماريهاى مادر- سابقه مصرف سيعار -

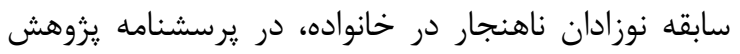

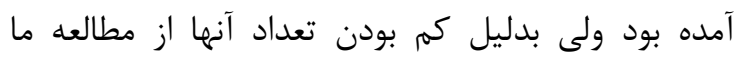

حذف شدند.

هر جند در اين مطالعه شيوع ناهنجارى در پسران كمى

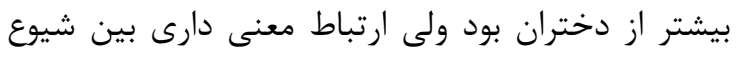

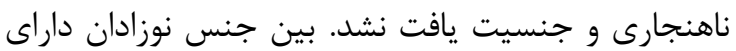

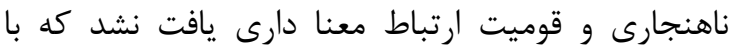
مطالعه شجرى و همكارانش مطابقت داشت

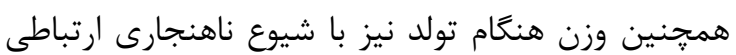
نداشت ولى در برخى از مطالعات، ميزان ناهنجارى با وزن

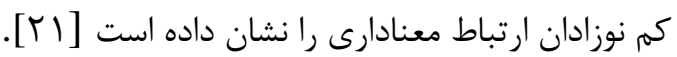

كمترين ميزان بروز مربوط به ناهنجاريهاى شكم ه/ه. مى

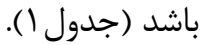
از نظر وضيعت اقتصادى خانوار، •.9. نوزادان ناهنجار در

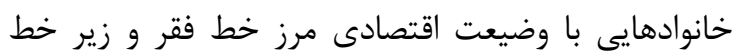
فقر بودند. در \$ه٪ نوزادان مبتلا به ناهنجارى، والدين نسبت فاميلى با يكديكر داشتند. اما بين نوع ناهنجارى و

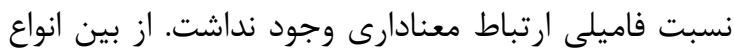
ناهنجارى در نوزادان يسر، ناهنجارى طناب عصبى و و كوش، حلق، بينى و صورت بيشترين رتبه را به خود اختصاص داده است در حالى كه تنها ناهنجارى كوش، حلق، بينى و صورت بيشترين ناهنجارى در نورادان دختر

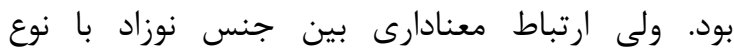
ناهنجارى ديده نشد. ميانگَين سنى مادران بود و كمترين سن 19 و بيشترين سن رئ سال بود.

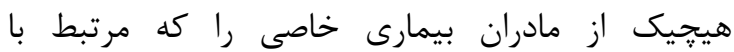
ناهنجارى در نوزاد باشد كزارش نكرده بودند و سابقه دانه

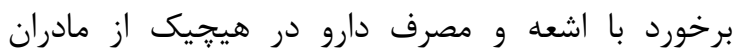

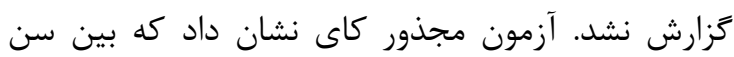

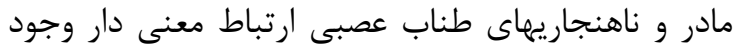

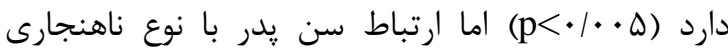

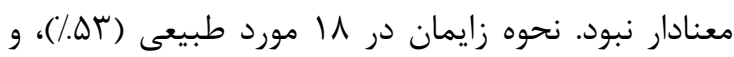

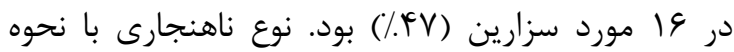
زايمان ارتباط معنى دارى نداشت. متوسط دور سر نوزادان

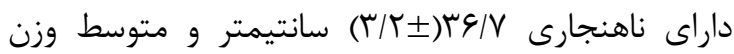

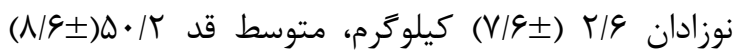

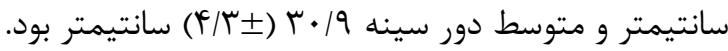
هيج يك از معيارهاى فوق در دو كروه داراى ناهنجارى و

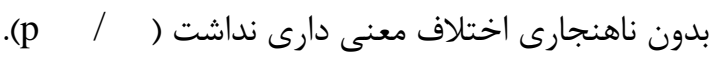
بحث يافته هاى اين يُوهش نشان داد كه ميزان بروز ناهنجارى

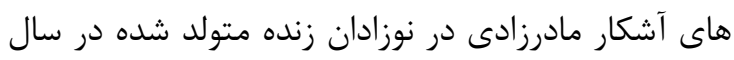

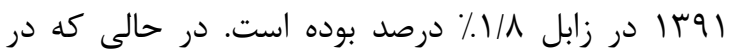

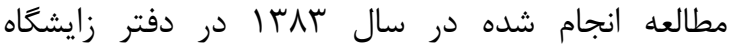

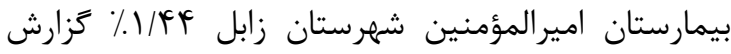

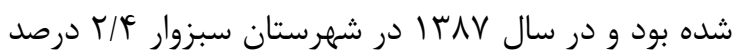
و در تهران //T درصد كزارش شده بود. در يك مطالعه

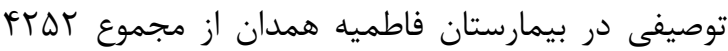


ماه اول تشخيص داده مى شوند بنابراين شيوع ذكر شده كمتر از مقدار واقعى است.

\section{نتيجه كيرى}

آموزش همعانى جهت در نظر كرفتن سن مناسب باردارى،

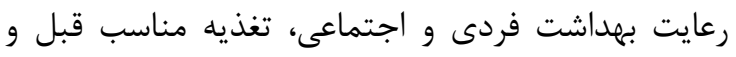
دوران باردارى به منظور پيشگيرى از بروز ناهنجاريها

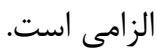

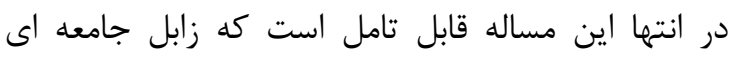
هموزن با ميزان بالاى ازدواج خويشاوندى است، احتمالا

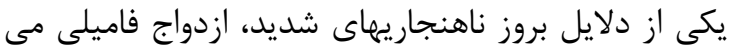

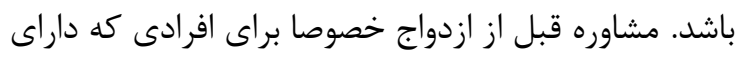

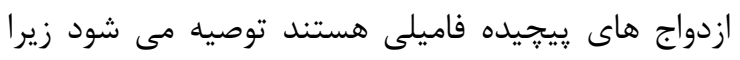
ارث يك فاكتور مهمم در بروز ناهنجاريهاست.

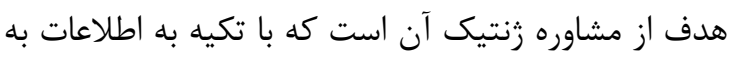

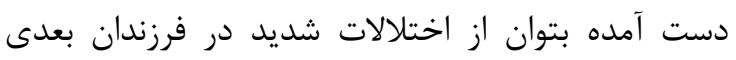

$$
\text { جلوكيرى كرد. }
$$

تشكر و قدردانى

بر خود لازم مى دانيم تا از كاركنان محترم زايشكاه در

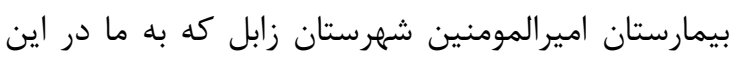
مطالعه يارى رساندند سياسخزارى كنيه. مطالعه حاضر

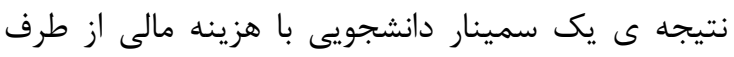

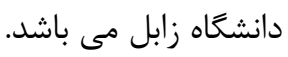

شيوع ناهنجاريهاى صورت، گَوش و حلق و بينى در اين منطقه قابل تامل است؛ اقليم جغرافيايى منطقه زابل، نبود

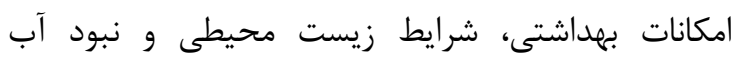

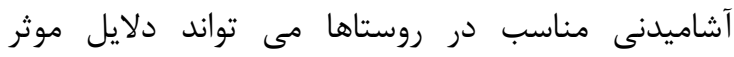

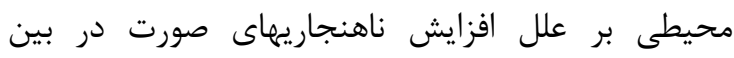
نوزادان باشد. يائين بودن سطح اجتماعى- اقتصادى يكى

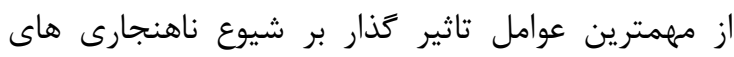

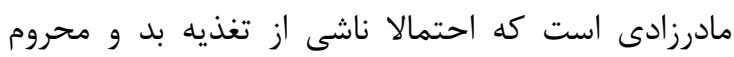

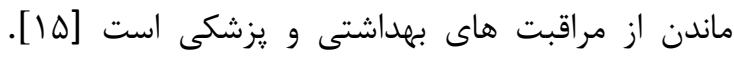

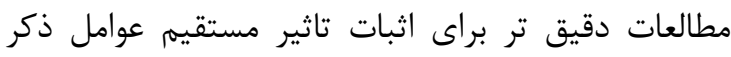
شده بر شيوع ناهنجارى لازم الاجراست.

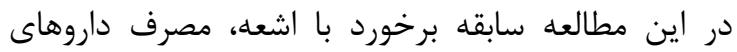
تراتورن و بيمارى هاى خاص مادر ديده نشد كه با بالي

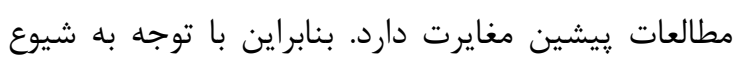

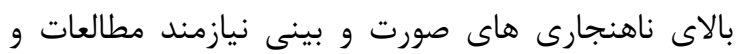
آموزش همعانى كَترده تر در اين منطقه است.

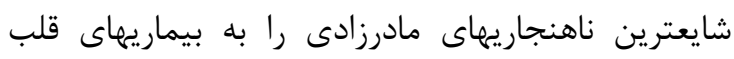

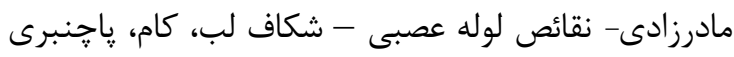

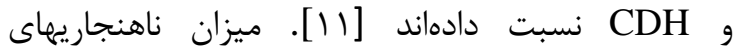
مادرزادى با افزايش سن مادر افزايش مىيابد كه در اين إنان

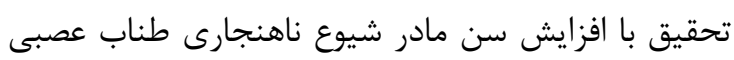

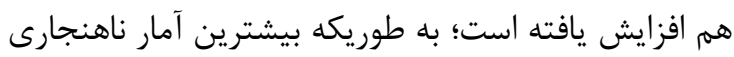

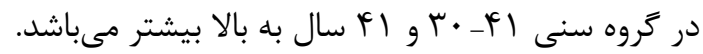
با توجه به محدوديت تعداد نمونه در مطالعه انجام شده

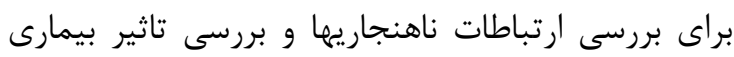

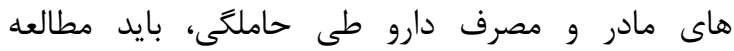

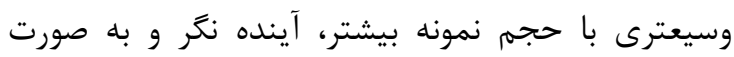

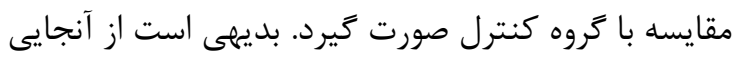
كه مطالعه حاضر فقط در يك مركز درمانى صورت كرفته

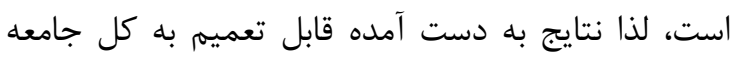

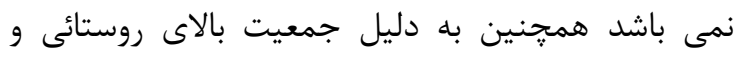

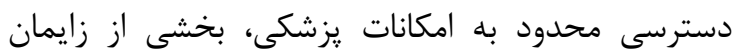

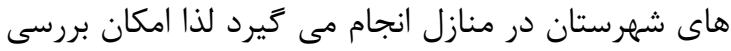

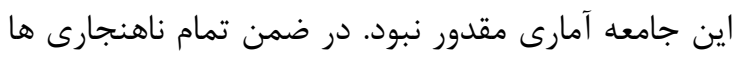

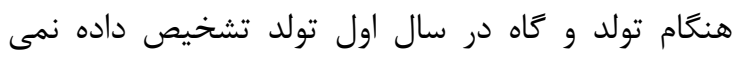

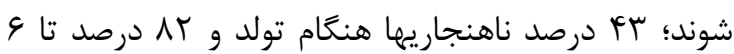




\section{References}

1. Ahmadzadeh A, Safikhani Z, Abdulahi M, Ahmadzadeh A, congenital malformations among live births at arvand hospital, ahwaz,iran - a prospective study, Pak J Med Sci January - March 2008 Vol. 24 No. 1 33-37 [ Persian].

2. 2-Longman Medical Embryology,Sadler T. W. $9^{\text {th }}$ ED,Williams Wilkins, 2005.

3. Tayebi N, Yazdani K, Naghshin N, The Prevalence of Congenital Malformations and its Correlation with Consanguineous Marriages,OMJ. 25, $\quad 37-40 \quad 2010$; doi:10.5001/omj.2010.9. [ Persian].

4. Safikhani Z, Ahmadzadeh A, Kalantar Mahdavi S.R, Abdolahi M, Moradi L, Frequency of external genitourinary system anomalies among male newborns in Ahvaz, Modern Care, Scientific Quarterly of Birjand Nursing and Midwifery Faculty, 2011.Vol 7, No. 3,4[ Persian].

5. Garry VF, Harkins ME, Erickson LL, Long-Simpson LK, Holland SE, Burroughs BL, Bilth defects, season of conception, and sex of children born to pesticide applicators living in the red River valley of Minnesota, usA, Environ Healt perspect, 2002, 110(3); 441-9.

6. Dastgiri S, Stone D H, Le-Ha C, Gilmour W H, anomalies in Glasgow, UK Prevalence and secular trend of congenital, Arch Dis Child. 2002 86: 257-263.

7. Mozafari Kermani R, Nedaeifard L, Nateghi M, Fazeli S, Ebrahim A, Ahmadi M, "et al", Congenital Anomalies in Infants Conceived by Assisted Re-productive Techniques, Archives of Iranian Medicine, 2012;15(4): 228 - 231[ Persian].

8. Parmar A, Rathod S, Patel S, A Study of Congenital Anomalies In Newborn, NJIRM 2010; Vol. 1(1). Jan-March.

9. Carlson BM, Human embryology and developmental biology, 2ed edition, Baltimore: Mosby Company, 1998; p: 128-195.

10.-Youman S, Neurological Surgery.3rd Ed, New York; NY; 1990; (2): p. 39; 40.

11.Lounne Hudgins, S.B Cassidy, Congenital Anomalies, In: Avory A. Fanaroff, R.J Martin, Neonatal-Perinatal Medicine: Diseases of the Fetus nd infant. 7th ed. St. Louis: Mosby, 2002, 488- 509.
12. Scott D, McLean, Congenital anomalies, In: Gordon B. Avery, M.A Fletcher and M.G MacDonald, Neonatology: Pathophysiology and Management of the Newborn. 5th ed. Philadelphia: Lippincott Williams\& Wilkins, 1999, 839-58.

13.Mohammed Y,. Shawky R, Amal A.S. Ahmed S, Chromosomal study in newborn infant $s$ with congenital anomalies in Assiut University hospital Cross-sec tional study, The Egyptian Journal of Medical Human Genetics ,2011. 12, 79-90[ Persian].

14.Marden PM, Smith DW, McDonald MJ, Congenital anomalies in the newborn infan, including minor variations, A study of 4412 babies by surface examination for anomalies and buccal smear for sex chromatin, J Pediatr 1964; 64: 357-71.

15.Shajari H, Mohammadi N, Karbalai Aghai M, Prevalence of congenital malformations observed in neonates in Shariati Hospital (2000-2003), Iran J Pediatr. 2006, Vol 16, No 3[ Persian].

16.Pober B, Overview of epidemiology, genetics, birth defects and chromosome abnormalities associated with $\mathrm{CDH}, \mathrm{Am} \mathrm{J}$ Med Genet Part C Semin Med Genet. 2007. 145C: $158-171$.

17.Leppig KA, Werler MM, Caron CI, et al. Predictive value of minor abnormalities: association with major malformations. $\mathrm{J}$ Pediatr 1987; 110: 531-537.

18.Erickson JD, Racial variations in the incidence of congenital malformations, Ann Hum Genet 1976; 39: 315- 20.

19.Rosano A, Botto LD, Botting B, "et al", Infant mortality and congenital anomalies from 1950 to 1994: an international perspective, Epidemiol Community Health 2000; 54: 6606.

20.Obu H, inawa J, Ulean ya N, Adimora G, E Obi I, Congenital malformations among newborns admitted in the neonatal unit of a tertiary hospital in Enugu, South-East Nigeria - a retrospective study. Obu ,"et al", BMC Research Notes 2012, 5:177.

21.Louanne H, Suzanne B, Cassidy congenital anomalies, In: Fanaroff M. Neonatal Perinatal Medicine, 8th ed. Philadelphia, mosby, 2006 Pp:561-82. 


\title{
Race of apparent abnormalities in neonates born in Amir- almomenin hospital of Sistan
}

\author{
Hosseini $S^{1,2}$, Nikravesh $A^{3}$, Hashemi $Z S^{4}$, Rakhshi $N^{5 *}$ \\ ${ }^{1}$ Department of Biology, Faculty of Sciences, University of Zabol, Iran \\ ${ }^{2}$ Pardis Clinical and Genetics Laboratory, Mashhad, Iran \\ ${ }^{3}$ Department of Molecular Sciences, Faculty of Medicine, North Khorasan University of Medical Sciences, \\ Bojnurd, Iran \\ ${ }^{4}$ Department of Midwifery, Faculty of Nursing and Midwifery, Zabol University of Medical Sciences, Zabol, \\ Iran \\ ${ }^{5}$ Department of Nursing and Midwifery, Islamic Azad University, Bojnourd branch, Bojnourd, Iran
}

\author{
*Corresponding Author: \\ Islamic Azad University, \\ Bojnourd branch, Bojnourd, \\ Iran \\ E-mail: \\ nahid.rakhsh52@gmail.com
}

\begin{abstract}
Background \& Objectives: Congenital abnormalities are essential causes of morbidity and mortality in neonates. Congenital disorders are diseases which develop during egg fertilization or during embryo development. The prevalence of affected infants that are born alive is estimated about 3-5\%. .This study has been performed on revealed malformations of the infants born in Sistan region.
\end{abstract}

Material \& Methods: This descriptive cross-sectional analysis was performed on all infants born alive and the congenital anomalies were detected from 1800 infants in three months. Sex, gestational age, type of abnormality, and neonate's status at discharge were recorded in a questionnaire. The data was analyzed by the spss 19 and chi-square test software.

Results: The prevalence of abnormalities was 1/8\%. There was a significant difference between maternal age and the incidence of congenital anomalies $(P \unlhd .05)$. According to our findings, the prevalence of congenital malformation especially abnormalcy of the ear, eye and face was $29.5 \%$.

Conclusion: The prevalence of congenital anomalies in year 1391 was higher than 1383 in Sistan region. Thus, more medical attention should be paid to their diagnosis and treatment at early stage. Also educational programs on congenital malformations and the consequences of consanguineous marriages should be performed.

Keywords: apparent anomalies, birth, stillborn, consanguineous marriage

Submitted:2 Mar 2014

Revised:19 May 2014

Accepted:27 Oct 2014 